\title{
Feeding strategies in pediatric cancer patients with gastrointestinal mucositis: a multicenter prospective observational study and international survey
}

\author{
Nicoline S.S. Kuiken ${ }^{1,2}$ • Edmond H.H.M. Ringss ${ }^{3,4}$ • Marry M. van den Heuvel-Eibrink ${ }^{5}$ • \\ Marianne D. van de Wetering ${ }^{6}$ - Wim J.E. Tissing ${ }^{1}$
}

Received: 13 December 2016/Accepted: 17 April 2017 /Published online: 26 April 2017

(C) The Author(s) 2017. This article is an open access publication

\begin{abstract}
Introduction Currently, there is no adequate prevention or treatment for both oral and gastrointestinal mucositis induced by chemotherapy and/or radiotherapy. Supportive care of symptoms plays a primary role during mucositis in the pediatric clinical setting. We aimed to get insight in the currently used feeding strategies in clinical practice in pediatric cancer patients with chemotherapy-induced mucositis.

Methods A prospective observational study was performed to identify feeding strategies after chemotherapy courses causing mucositis in almost all patients at the University Medical Center Groningen (UMCG), the Academic Medical Center Amsterdam (AMC), and the Princess Maxima Center Utrecht (PMC). Consecutive patients, aged 0-18 years, either
\end{abstract}

Electronic supplementary material The online version of this article (doi:10.1007/s00520-017-3715-7) contains supplementary material, which is available to authorized users.

Wim J.E. Tissing

w.j.e.tissing@umcg.nl

1 Department of Pediatric Oncology, Beatrix Children's Hospital, University of Groningen, University Medical Center Groningen, PO Box 30001, 9700 RB Groningen, The Netherlands

2 Department of Pediatric Gastroenterology and Hepatology, Beatrix Children's Hospital, University of Groningen, University Medical Center Groningen, Groningen, The Netherlands

3 Department of Pediatrics, Leiden University Medical Center, Leiden University, Leiden, The Netherlands

4 Department of Pediatrics, Erasmus Medical Center Rotterdam, Erasmus University Rotterdam, Rotterdam, The Netherlands

5 Princess Maxima Center for Pediatric Oncology, Utrecht, The Netherlands

6 Department of Pediatric Oncology, Academic Medical Center, University of Amsterdam, Amsterdam, The Netherlands diagnosed with B cell non-Hodgkin lymphoma (B-NHL) or scheduled for autologous stem cell transplantation (SCT) between April 2015 and September 2016 were included in this study. In addition to the observational study in the Netherlands, an international online questionnaire was conducted for pediatric oncology centers.

Results A total of 13 patients were included, after 21 chemotherapy courses. No nutritional support was administered after $23.8 \%$ courses, tube feeding after $19.0 \%$ of the courses, TPN in $19.0 \%$ of courses, and $38.1 \%$ received a combination of tube feeding and TPN. The international survey revealed that $63.2 \%$ of the centers administered tube feeding as first choice, $31.6 \%$ administered only TPN as first choice, and one center administered a combination as first choice.

Conclusions There is a variability in feeding strategies in the clinical practice both in the Netherlands as well as worldwide. This study is a basis for future studies in this important clinical field to develop clinical trials comparing tube feeding and TPN both in adult and pediatric patients.

Keywords Mucositis $\cdot$ Feeding strategy $\cdot$ Pediatric cancer patients

\section{Introduction}

Mucositis is a severe side effect of both chemotherapy and radiotherapy and can be subdivided in oral and gastrointestinal (GI) mucositis. Patients suffering from GI mucositis have symptoms like pain, vomiting, diarrhea, and a decreased intake, resulting in a decreased quality of life [1-3]. Moreover, the patients are at increased risk to develop a bacteremia or sepsis. Eventually, this may lead to a lower chemotherapeutic dose or delay in the next chemotherapy course, possibly influencing survival. Currently, there is no adequate 
prevention or treatment for both oral and GI mucositis. Only supportive care of symptoms plays a primary role during mucositis in the pediatric clinical setting [4]. During oral mucositis, the mouth is painful and oral intake may be difficult, but in many patients, the intestine is still functioning and could be used in, for example, enteral tube feeding [5]. However, during GI mucositis, it is questionable if the intestine can still digest and absorb the nutrients during mucositis. Previous clinical studies have shown that at the time of mucositis, the absorption of lactose is reduced, but amino acids can still be absorbed [6, 7]. Furthermore, from animal studies, we know that glucose and amino acids could still be absorbed if enterally administered continuously $[8,9]$. In contrast, lactose and fatty acids were not absorbed even if continuously administered enterally $[10,11]$. Even more, total enteral nutrition was not feasible, and total parenteral nutrition (TPN) was superior to maintain weight in rats [12]. Recently, it was shown that minimal enteral feeding was feasible and possibly alters recovery after mucositis in a rat model [13]. In general, nutritional support in pediatric cancer patients is challenging, there is no consistency, and both enteral nutrition and TPN have advantages and disadvantages $[14,15]$. Tube feeding is not ideally during nausea and vomiting. On the other hand, TPN may induce villus atrophy and mucosal permeability in the intestine [16-18]. Furthermore, adult patients with early initiated TPN had more infections, 26 versus $22 \%$ and a higher incidence of cholestasis [19]. Even more, liver dysfunction in critically ill patients developed in 30\% in TPN patients versus $18 \%$ in patients with enteral nutrition [20]. Unfortunately, no clinical studies have been performed concerning nutritional support during mucositis [15]. Therefore, clinical trials concerning feeding strategies during mucositis are needed. However, it is important to know the current clinical practice in order to design clinical trials. Therefore, we set up this research project to get insight in the currently used feeding strategies in clinical practice in pediatric cancer patients with chemotherapy-induced mucositis. We determined the feeding strategy in a multicenter observational study in the Netherlands prospectively. In addition, an online survey was conducted among healthcare professionals internationally, to get more insight in the diagnosis and treatment protocols of both oral and GI mucositis, and thereby determine the differences and/or concordances between pediatric oncology centers internationally.

\section{Materials and methods}

\section{Observational study}

\section{Study and subjects}

A prospective observational study was performed to identify feeding strategies after chemotherapy courses causing mucositis in almost all patients. The study was done at the University Medical Center Groningen (UMCG), the Academic Medical Center Amsterdam (AMC), and the Princess Maxima Center Utrecht (PMC). Consecutive patients, aged $0-18$ years, either diagnosed with $\mathrm{B}$ cell nonHodgkin lymphoma (B-NHL) or scheduled for autologous stem cell transplantation (SCT) between April 2015 and September 2016 were included in this study. Patients with B-NHL were treated according to the Dutch Childhood Oncology Group (DCOG) treatment protocol [21-24] and were included after both COPADM1 and COPADM2 chemotherapy course. These two courses, consisting of vincristine, methotrexate, cyclofosfamide, doxorubicin, and prednisone, cause mucositis in almost all patients. Before stem cell transplantation in, for example, neuroblastoma patients, the conditioning regimen consisted of melphalan, etoposide, and carboplatin according to treatment protocol NBL-2009 from the DCOG [25], but other diagnoses with other conditioning regimens were also included, as shown in Table 1. The Medical Ethical Committee of the University Medical Center Groningen, Groningen, The Netherlands, exempted this study for ethical review board approval, since this study observed the current clinical practice and data were generated by routine medical care. For the use of the leftover material for research purposes, all patients and/or parents signed informed consent in general for the treatment protocol for their disease. This study was registered in the online trial register (number NTR5070).

\section{Study procedures}

When a patient was admitted in the UMCG, AMC, or PMC for a chemotherapy course according to the treatment protocol of B-NHL or for a conditioning regimen before autologous SCT, the patient was eligible for inclusion. During admission, the following items were registered after a chemotherapy course daily: feeding strategy, weight, pain score, and mucositis score. For the study purpose, nurses and doctors were instructed to score on a daily basis the severity of mucositis by using the National Cancer Institute Common Criteria for Adverse Events (NCI-CTCAE) criteria for gastrointestinal mucositis [26]. During admission, when regular blood sampling was performed, the remaining plasma was used to measure citrulline. Citrulline is an amino acid, a marker for the enterocyte mass corresponding with the severity of mucositis in both adult and pediatric patients as well as with villus length in a mucositis animal model [10,27-32]. Therefore, with citrulline, the level of mucositis could be checked during the study period. No extra blood samples were taken for study purpose only. The study ended when the patient was discharged from the hospital or at time of start of the next chemotherapy course. 
Table 1 Patient characteristics

\begin{tabular}{ll} 
Characteristic & \\
\hline Patients, $n$ & 13 \\
Chemotherapy courses, $n$ & 21 \\
Age, median (range) & $11(1-18)$ \\
Sex & $11(84.6)$ \\
$\quad$ Male, $n(\%)$ & \\
Diagnosis & 5 \\
B-NHL & 1 \\
Systemic EBV + T cell lymphoproliferative & \\
$\quad$ disease of childhood & \\
Neuroblastoma & 2 \\
Relapse ewing sarcoma & 1 \\
Medulloblastoma & 1 \\
Glioma & 1 \\
Relapse Hodgkin lymphoma & 1 \\
Relapse Wilms tumor & 1 \\
Chemotherapy courses & \\
COPADM1, $n(\%)$ & $6(28.6)$ \\
COPADM2, $n(\%)$ & $6(28.6)$ \\
Conditioning regimen for SCT,$n(\%)$ & $9(42.8)$ \\
Tube feeding before chemotherapy, $n(\%)$ & $5(23.8)$ \\
\hline
\end{tabular}

$B$-NHL B cell non-Hodgkin lymphoma, SCT stem cell transplantation

${ }^{a}$ Treatment according to the B-NHL protocol with COPADM1 and COPADM2 courses

${ }^{\mathrm{b}}$ Two patients received two times a SCT and were therefore included twice

\section{Data collection}

Data collection included age, sex, chemotherapy course, daily pain score (VAS score), daily mucositis score (NCI-CTCAE), daily registration of tube feeding, and/or parenteral nutrition administration. The use of analgesics, the number of bacteraemias, and the duration of hospital stay in days were looked up in the electronic patient record. Data were entered on predesigned standardized case report forms and later captured into an electronic database.

\section{Citrulline}

The serum citrulline was measured by using automated ion exchange column chromatography, as described before $[10$, $33,34]$.

\section{Online international survey}

In addition to the observational study in the Netherlands, an online questionnaire was conducted for pediatric oncology centers (Supplementary methods). The survey contained questions about the care of oral mucositis, the assessment/ diagnosis, prevention, treatment and pain management. Secondly, the survey contained information about GI mucositis, concerning the diagnosis, assessment scale, biomarker, nutritional support, prevention, treatment, and the use of prebiotics or probiotics. The survey was available online via a link on the International Society of Pediatric Oncology (SIOP) website. The survey was also distributed via SIOP and Multinational Association of Supportive Care in Cancer (MASCC) mailing lists.

\section{Statistical analysis}

Statistical analysis was done using SPSS version 22.0 for Windows (SPSS Inc., Chicago, IL, USA). We used descriptive statistics for all values, both in the prospective observational study and in the international survey. All values express mean and standard deviation if parameter is normal distributed. Non-parametrical data are expressed as median and range.

\section{Results}

\section{Prospective observational study}

\section{Patient characteristics}

A total of 13 patients were included, after 21 chemotherapy courses as shown in Table 1. The median age was $11(1-18)$ years, and most patients were male (84.6\%). Before start of the chemotherapy course, five patients already received nutritional support which was tube feeding in all cases. All five patients with B-NHL and one patient with systemic EBV + T cell lymphoproliferative disease of childhood, treated according to the B-NHL protocol, were included after both COPADM1 and COPADM2 course. Patients scheduled for an autologous stem cell transplantation (SCT) were included after the conditioning regimen $(n=7)$. Two patients received a second SCT and were therefore included twice, after both conditioning regimens.

\section{Feeding strategy}

In one center, it was standard care to start with TPN after stem cell reinfusion in every patient, independent of the nutritional status, and tube feeding was only added when the patients' clinical condition improved and they could tolerate enteral feeding. In all other patients and in the two other centers, it was standard care to start with tube feeding in case of decreased oral intake, and TPN was only administered if tube feeding was not tolerated due to vomiting, abdominal discomfort, or diarrhea. The feeding strategy was very diverse as shown in Table 2 and Fig. 1. No 
nutritional support was administered after $23.8 \%$ courses. After $19.0 \%$ of the chemotherapy courses, only tube feeding was administered. After $19.0 \%$ of the courses, only TPN was administered, of which three patients in the center where it was standard care to start TPN after stem cell reinfusion and one based on patient preferences. The nutritional support administered after most courses, $38.1 \%$, was a combination of tube feeding and TPN, of which after seven courses as first step, tube feeding was started, and secondly, TPN was added because total enteral tube feeding was not tolerated. After one course, first TPN was started, and then, as second step, tube feeding was added when the patient tolerated enteral feeding.

\section{Nutritional status}

Figure 2 shows the largest bodyweight change after a chemotherapy course in percentage compared with the bodyweight before a chemotherapy course. As shown, in most patients without nutritional support or with tube feeding alone, there was a decrease in bodyweight. Nine patients receiving either TPN or tube feeding + TPN seemed to increase in bodyweight, without another specific reason to declare the remarkable increase in bodyweight. This may be due to either overfeeding or an increase in fluids because of increased illness.

\section{Mucositis and pain score}

The median highest mucositis score after chemotherapy courses was $3(1-4)$. The median highest pain score after chemotherapy courses, specifically abdominal pain, was 3 (0-9). Furthermore, pain medication was administered after 20 courses $(95.2 \%)$, as shown in Table 2. Proportionally, the most morphine was administered in the group where the combination of tube feeding + TPN was administered, suggesting that these patients suffered from more severe mucositis.

\section{Citrulline}

Figure 3 shows the lowest plasma citrulline levels measured between day 5 and day 13 after the chemotherapy course. Most patients receiving TPN or tube feeding + TPN had a lowest citrulline level below $10 \mu \mathrm{mol} / \mathrm{l}$, reflecting severe mucositis, of which most received a conditioning regimen [35].

\section{Infections}

The patients developed fever and were consequently treated with ceftazidim and/or vancomycin after 14 (66.7\%) chemotherapy courses, as shown in Table 2. Patients with TPN had more episodes of fever with antibiotic treatment $(n=10)$

Table 2 Feeding strategy

\begin{tabular}{|c|c|c|c|c|c|}
\hline & $\begin{array}{l}\text { No } \\
\text { nutritional } \\
\text { support } \\
(n=5)\end{array}$ & $\begin{array}{l}\text { Tube feeding } \\
(n=4)\end{array}$ & $\begin{array}{l}\text { TPN } \\
(n=4)\end{array}$ & $\begin{array}{l}\text { Tube feeding }+ \text { TPN } \\
(n=8)\end{array}$ & $\begin{array}{l}\text { Total courses } \\
(n=21)\end{array}$ \\
\hline Age, median (range) & $13(11-15)$ & $10.5(10-15)$ & $13(10-18)$ & $6(1-16)$ & $11(1-18)$ \\
\hline Highest mucositis score, median (range) & $2(1-3)$ & $1.5(1-2)$ & $1(1-3)$ & $3(2-4)$ & $3(1-4)$ \\
\hline Highest pain score, median (range) & $0(0-4)$ & $3(0-6)$ & $2(0-8)$ & $7(3-9)$ & $3(0-9)$ \\
\hline \multicolumn{6}{|l|}{ Pain medication } \\
\hline Paracetamol, $n(\%)$ & $5(100 \%)$ & $4(100 \%)$ & $3(75 \%)$ & $8(100 \%)$ & $20(95.2 \%)$ \\
\hline Tramadol, $n(\%)$ & $4(80 \%)$ & $3(75 \%)$ & $1(25 \%)$ & $6(75 \%)$ & $14(66.7 \%)$ \\
\hline Morphine, $n(\%)$ & $1(20 \%)$ & $1(25 \%)$ & $2(50 \%)$ & $6(75 \%)$ & $10(47.6 \%)$ \\
\hline Other, $n(\%)$ & $0(0 \%)$ & $1(25 \%)$ & $1(25 \%)$ & $4(50 \%)$ & $6(28.6 \%)$ \\
\hline Vomiting, $n(\%)$ & $0(0 \%)$ & $1(25 \%)$ & $1(25 \%)$ & $3(37.5 \%)$ & $5(23.8 \%)$ \\
\hline Diarrhea, $n(\%)$ & $0(0 \%)$ & $1(25 \%)$ & $0(0 \%)$ & $5(62.5 \%)$ & $6(28.6 \%)$ \\
\hline $\begin{array}{l}\text { Episode with fever for which treatment } \\
\text { with ceftazidim and/or vancomycin, } n(\%)\end{array}$ & $3(60 \%)$ & $1(25 \%)$ & $3(75 \%)$ & $7(87.5 \%)$ & $14(66.7 \%)$ \\
\hline After start of TPN & & & 3 & 4 & \\
\hline Before start of TPN & & & & 2 & \\
\hline Simultaneously with start of TPN & & & & 1 & \\
\hline Positive blood culture, $n(\%)$ & $2(40 \%)$ & $0(0 \%)$ & $1(25 \%)$ & $3(37.5 \%)$ & $6(28.6 \%)$ \\
\hline $\begin{array}{l}\text { Hospital stay after chemotherapy course in days, } \\
\text { mean } \pm \text { SD }\end{array}$ & $13.8 \pm 2.4$ & $11 \pm 4.3$ & $15.5 \pm 2.1$ & $17.5 \pm 5.9$ & $15 \pm 4.9$ \\
\hline
\end{tabular}

Tube feeding pain score $n=3$, mucositis score $n=2$, tube + tpn pain score $n=7$ 
Fig. 1 Feeding strategy. Feeding strategy after the chemotherapy course. The bars represent the number of days the nutritional support was administered. Every row represents one course.

Twenty-one courses in total. After five COPADM courses, no nutritional support was administered

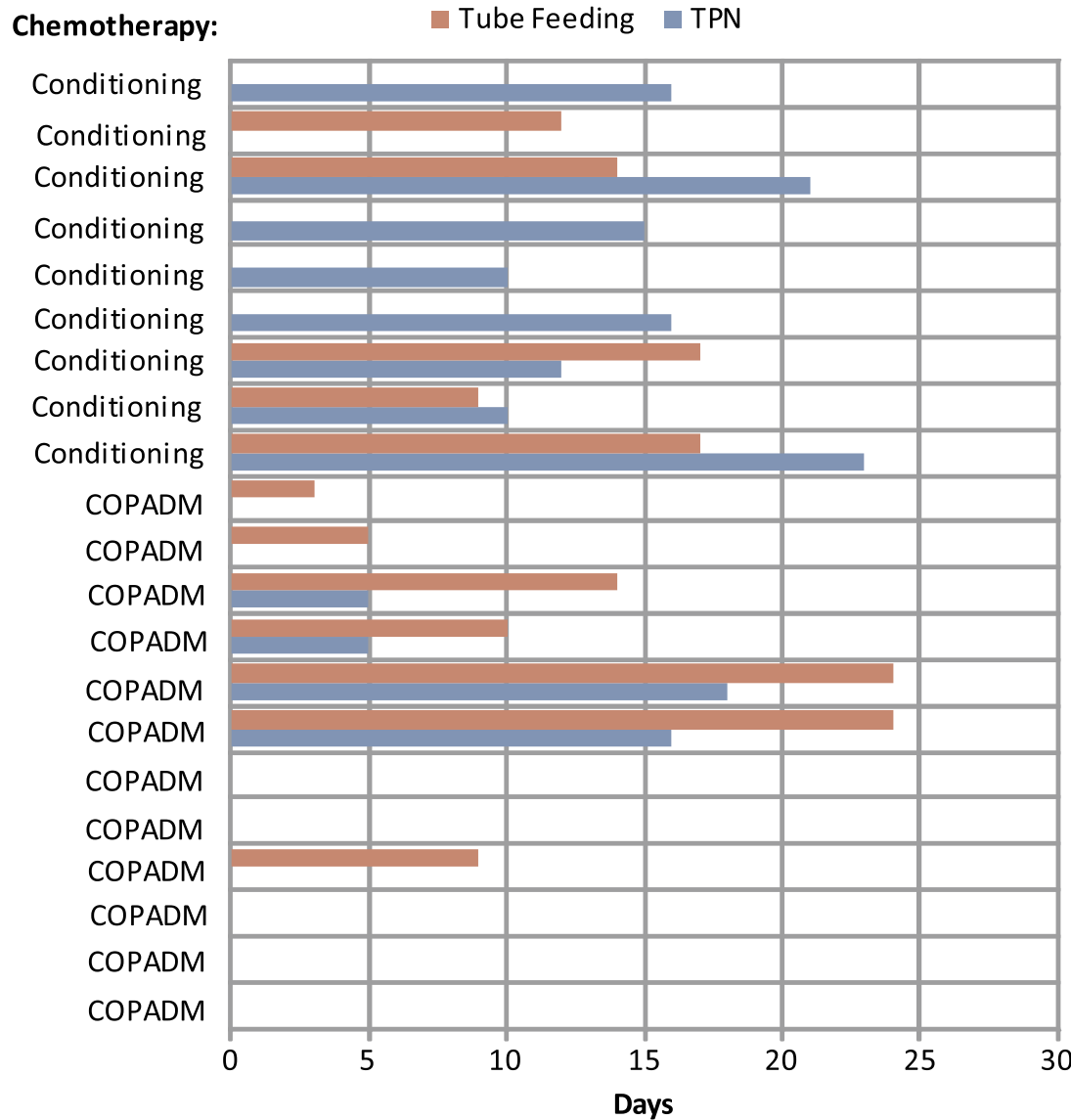

combines the NCI-CTCAE and the WHO scale (6.7\%), and 2 hospitals use their own developed scoring scale (13.3\%).

\section{Pain medication during oral mucositis}

Mostly used pain medication during oral mucositis is morphine (85\%), paracetamol (55\%), tramadol (40\%), and topical pain medication like mouthwash containing lidocaine $(25 \%)$, and a minority also uses NSAIDs (10\%) as analgesia during oral mucositis.

\section{Prevention and treatment of oral mucositis}

The most prevalent intervention as prevention is mouthwash $(50 \%)$ and oral cryotherapy (20\%). In $7 / 20$ centers $(35 \%)$, no prevention is given. For treatment of oral mucositis, interventions like mouthwash (35\%) and low-level laser therapy $(5 \%)$ are used. In 10/20 centers (50\%), no intervention is used as treatment.

\section{Diagnosis of gastrointestinal mucositis}

In $14 / 20$ centers $(70 \%)$, the diagnosis of GI mucositis is only based on clinical symptoms like vomiting, abdominal discomfort, and diarrhea. Some centers $(20 \%)$ combine the clinical sessment scale, mostly the NCI-CTCAE (33.3\%), WHO scoring scale (33.3\%), and ChIMES self-scoring scale (13.3\%), 1 


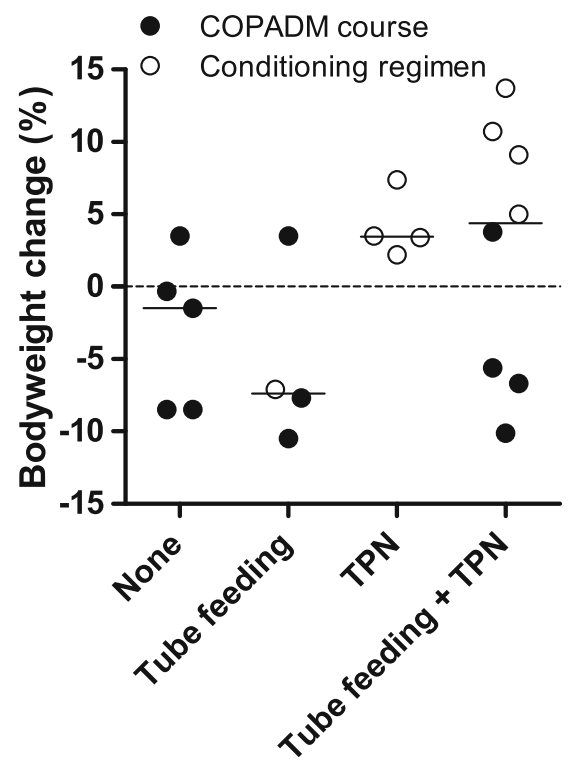

Fig. 2 Bodyweight change. Largest bodyweight change in days after chemotherapy course, in percentage compared to bodyweight prior to chemotherapy. Between day 1 and day 11. The line is the median. Dots represent individuals after chemotherapy course

symptoms with the NCI-CTCAE scoring scale. One center combines the clinical symptoms with the daily gut score. One center combines the clinical symptoms with the NCICTCAE score and fecal calprotectin as biomarker.

\section{Feeding strategy during GI mucositis}

Nineteen of 20 respondents answered the questions about nutritional support as shown in Fig. 4. In 13/19 centers, tube feeding is administered as first choice for nutritional support during mucositis and parenteral nutrition as second choice. In $3 / 19$ centers, they administer parenteral nutrition as first choice and tube feeding as second choice; all of these centers are located in Northern America. Two centers, in Spain and Macedonia, do not administer tube feeding at all, only parenteral nutrition. One center chooses directly for a combination of both as nutritional support. If tube feeding is administered, in $5 / 19$, this is the normal standard diet. In $8 / 19$ centers, a semi-elemental diet is given as tube feeding. Two centers administer elemental diet. Two centers are not sure, and in two centers, it is the decision of the dietician. If parenteral nutrition is administered, 12/19 centers add minimal enteral feeding (MEF) via tube. Three centers administer MEF sometimes, and four centers do not administer MEF as additive to parenteral nutrition.

\section{Prebiotics or probiotics}

Four centers administer prebiotics or probiotics occasionally, for example, Linex ${ }^{\circledR}$ or Biopron ${ }^{\circledR}$, but the majority does not administer any prebiotic or probiotic.

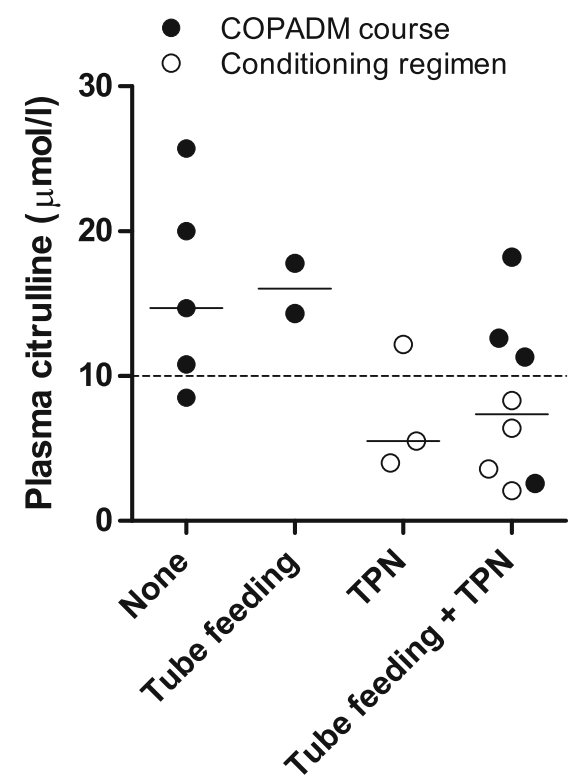

Fig. 3 Plasma citrulline. Lowest plasma citrulline measured in the days after chemotherapy treatment. Each dot represents individuals after chemotherapy treatment. The line is the median per feeding strategy. All samples were measured between day 5 and day 13 after chemotherapy course

\section{Discussion}

This is the first study addressing nutritional support during chemotherapy-induced mucositis and aimed to get insight in the current feeding strategy during chemotherapy-induced mucositis in pediatric cancer patients. Our results showed the variability in feeding strategies concerning tube feeding, TPN, type of diet, and administration of MEF. There is no consensus between centers in the Netherlands or worldwide. The feeding strategy is currently dependent on patients and doctors' preferences.

This observational study showed that within three centers in the Netherlands, there was already a different standard care for nutritional support during mucositis. The results showed that one center started TPN in all patients receiving stem cell transplantation and only added tube feeding after the patient improved his/her blood count and tolerated enteral feeding. In all other cases, nutritional support was only administered in case of a decrease in bodyweight. The first choice in all centers was tube feeding, and TPN was only added in case of intolerance of total tube feeding, for example, due to vomiting. Although it is only an explorative study, the results may give a few suggestions. First, the results suggest that TPN caused a better nutritional status after chemotherapy courses, compared to the weight loss when no nutritional support or tube feeding only was administered. Secondly, in contrast, the results suggest that the administration of TPN was associated with more episodes of fever for which antibiotic treatment was started. In most of these cases, fever with antibiotic treatment developed after the start of TPN. Furthermore, patients receiving TPN 

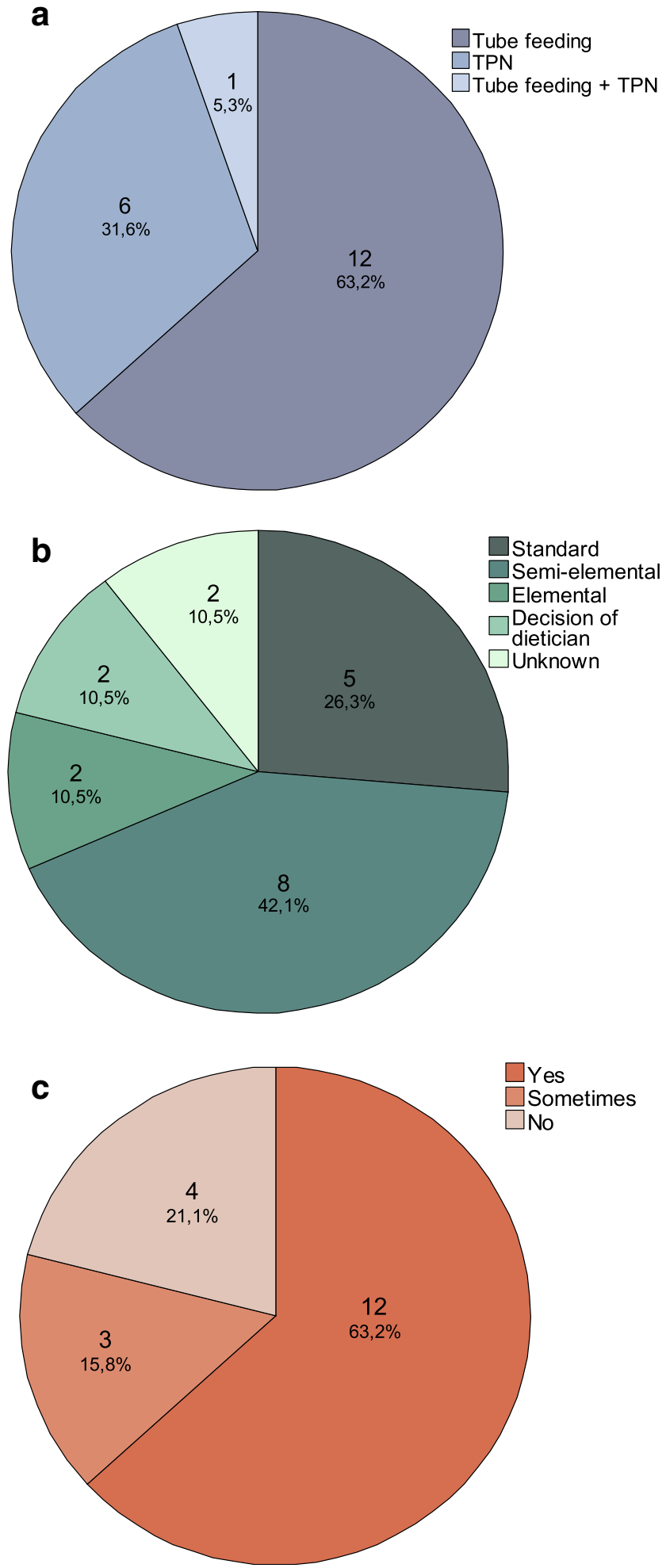

Fig. 4 Feeding strategy during mucositis. In 19 centers worldwide. a Survey question: What is the first choice of nutritional support? b Survey question: Which diet is administered as tube feeding. c Survey question: Is minimal enteral feeding administered as additive to total parenteral nutrition?

were hospitalized for more days after chemotherapy compared to patients without TPN. The pain medication and citrulline levels suggested more severe mucositis in the patients receiving TPN. Therefore, this suggests that the patients receiving TPN were more severely ill, which might have contributed to the prolonged hospitalization.

The results from the survey, although a small number of centers participated, also suggest that there are intercenter differences in feeding strategies. Tube feeding, TPN, or a combination of both are all first choice as nutritional support. Furthermore, in the majority of centers, minimal enteral feeding is added to TPN if it is feasible; however, a few centers do not administer tube feeding at all. Moreover, the result show that also in pain management, there are many differences between centers.

Since this was the first study concerning feeding strategies during mucositis, we could not compare the results to other studies in patients with mucositis. However, in a systematic review concerning critically ill pediatric patients, it was also concluded that there was a lack of data and the main conclusion was that research is urgently needed [36]. Recently, one study determined the difference between early and late parenteral nutrition in critically ill pediatric patients. They showed that late parenteral nutrition was superior, for, among other things, less new infections and a shorter duration hospital stay [37]. This is comparable to the suggestions of our results. Furthermore, in children undergoing allogeneic hematopoietic stem cell transplantation, not specifically during mucositis, enteral nutrition is suggested to be the first option and parenteral nutrition the second [38]. Additionally, a systematic review concerning nutritional support in children with cancer receiving chemotherapy, not specifically mucositis, suggested that TPN might be superior compared to normal food intake [39]. However, not one study compared tube feeding with TPN, and the main conclusion was that further research is essential.

A limitation of this study is that it was only an observational study in a small amount of patients, in which we were not able to do an appropriate analysis, but only descriptive statistics. We were therefore not able to draw conclusions about the best feeding strategy during mucositis, both in the observational study as well as the survey. However, we aimed to show the currently used feeding strategies in the clinical practice in pediatric cancer patients with chemotherapyinduced mucositis. Therefore, this study may contribute to the design of clinical trials comparing feeding strategies and eventually the development of guidelines to improve the clinical practice.

In conclusion, since there are both discordances in the clinical practice in the Netherlands and worldwide, as well as a lack of knowledge, we are in need of a clinical trial concerning feeding strategies during mucositis. In the meantime, based on our results in combination with literature, we suggest to administer tube feeding as first choice, with an easy access to TPN in case of decreased nutritional status or intolerance for 
tube feeding. Although TPN may be effective to stay in a good nutritional condition, we suggest to be careful to introduce TPN as first option as feeding strategy since it possibly increases the risk for infection. However, further research is needed to draw conclusions. Therefore, this study is a basis for future studies in this important clinical field to develop clinical trials comparing tube feeding and TPN both in adult and pediatric patients.

\section{Compliance with ethical standards}

Funding This work was supported by the Dutch Cancer Society (grant number RUG 2011-5272).

Conflict of interest The authors declare that they have no conflict of interest.

Open Access This article is distributed under the terms of the Creative Commons Attribution-NonCommercial 4.0 International License (http:// creativecommons.org/licenses/by-nc/4.0/), which permits any noncommercial use, distribution, and reproduction in any medium, provided you give appropriate credit to the original author(s) and the source, provide a link to the Creative Commons license, and indicate if changes were made.

\section{References}

1. Sonis ST, Elting LS, Keefe D, Peterson DE, Schubert M, HauerJensen M, Bekele BN, Raber-Durlacher J, Donnelly JP, Rubenstein EB, Mucositis Study Section of the Multinational Association for Supportive Care in Cancer, International Society for Oral Oncology (2004) Perspectives on cancer therapy-induced mucosal injury: pathogenesis, measurement, epidemiology, and consequences for patients. Cancer 100:1995-2025

2. Sonis ST (2004) The pathobiology of mucositis. Nat Rev Cancer 4: 277-284

3. Keefe DM, Schubert MM, Elting LS, Sonis ST, Epstein JB, RaberDurlacher JE, Migliorati CA, DB MG, Hutchins RD, Peterson DE, Mucositis Study Section of the Multinational Association of Supportive Care in Cancer and the International Society for Oral Oncology (2007) Updated clinical practice guidelines for the prevention and treatment of mucositis. Cancer 109:820-831

4. Lalla RV, Bowen J, Barasch A, Elting L, Epstein J, Keefe DM, DB MG, Migliorati C, Nicolatou-Galitis O, Peterson DE, RaberDurlacher JE, Sonis ST, Elad S, Mucositis Guidelines Leadership Group of the Multinational Association of Supportive Care in Cancer and International Society of Oral Oncology (MASCC/ ISOO) (2014) MASCC/ISOO clinical practice guidelines for the management of mucositis secondary to cancer therapy. Cancer 120:1453-1461

5. Bauer J, Jurgens H, Fruhwald MC (2011) Important aspects of nutrition in children with cancer. Adv Nutr 2:67-77

6. Hyams JS, Batrus CL, Grand RJ, Sallan SE (1982) Cancer chemotherapy-induced lactose malabsorption in children. Cancer 49:646-650

7. de Koning BA, van der Schoor SR, Wattimena DL, de Laat PC, Pieters R, van Goudoever JB (2007) Chemotherapy does not influence intestinal amino acid uptake in children. Pediatr Res 62:195199

8. Fijlstra M, Rings EH, van Dijk TH, Plosch T, Verkade HJ, Tissing WJ (2013) Continuous enteral administration can overcome the limited capacity to absorb glucose in rats with methotrexateinduced gastrointestinal mucositis. Support Care Cancer 21:863871

9. Fijlstra M, Schierbeek H, Voortman G, Dorst KY, van Goudoever JB, Rings EH, Tissing WJ (2012) Continuous enteral administration can enable normal amino acid absorption in rats with methotrexate-induced gastrointestinal mucositis. J Nutr 142:19831990

10. Fijlstra M, Rings EH, Verkade HJ, van Dijk TH, Kamps WA, Tissing WJ (2011) Lactose maldigestion during methotrexateinduced gastrointestinal mucositis in a rat model. Am J Physiol Gastrointest Liver Physiol 300:G283-G291

11. Fijlstra M, Tissing WJ, Stellaard F, Verkade HJ, Rings EH (2013) Reduced absorption of long-chain fatty acids during methotrexateinduced gastrointestinal mucositis in the rat. Clin Nutr 32:452-459

12. Fijlstra M, Tissing WJE, Verkade HJ, Rings EHHM (2013) Parenteral feeding during methotrexate-induced gastrointestinal mucositis prevents weight loss in the rat 8:e95-e99

13. Kuiken NS, Rings EH, Havinga R, Groen AK, Tissing WJ (2016) Effect of minimal enteral feeding on recovery in a methotrexateinduced gastrointestinal mucositis rat model. Support Care Cancer 24:1357-1364

14. Ladas EJ, Sacks N, Brophy P, Rogers PC (2006) Standards of nutritional care in pediatric oncology: results from a nationwide survey on the standards of practice in pediatric oncology. A Children's Oncology Group study. Pediatr Blood Cancer 46:339344

15. Kuiken NS, Rings EH, Tissing WJ (2015) Risk analysis, diagnosis and management of gastrointestinal mucositis in pediatric cancer patients. Crit Rev Oncol Hematol 94:87-97

16. Seres DS, Valcarcel M, Guillaume A (2013) Advantages of enteral nutrition over parenteral nutrition. Therap Adv Gastroenterol 6: 157-167

17. Feng Y, Ralls MW, Xiao W, Miyasaka E, Herman RS, Teitelbaum DH (2012) Loss of enteral nutrition in a mouse model results in intestinal epithelial barrier dysfunction. Ann N Y Acad Sci 1258: 71-77

18. Yang H, Feng Y, Sun X, Teitelbaum DH (2009) Enteral versus parenteral nutrition: effect on intestinal barrier function. Ann N Y Acad Sci 1165:338-346

19. Casaer MP, Mesotten D, Hermans G, Wouters PJ, Schetz M, Meyfroidt G, Van Cromphaut S, Ingels C, Meersseman P, Muller J, Vlasselaers D, Debaveye Y, Desmet L, Dubois J, Van Assche A, Vanderheyden S, Wilmer A, Van den Berghe G (2011) Early versus late parenteral nutrition in critically ill adults. N Engl J Med 365: 506-517

20. Grau T, Bonet A, Rubio M, Mateo D, Farre M, Acosta JA, Blesa A, Montejo JC, de Lorenzo AG, Mesejo A, Working Group on Nutrition and Metabolism of the Spanish Society of Critical Care (2007) Liver dysfunction associated with artificial nutrition in critically ill patients. Crit Care 11:R10

21. Patte C, Auperin A, Michon J, Behrendt H, Leverger G, Frappaz D, Lutz P, Coze C, Perel Y, Raphael M, Terrier-Lacombe MJ, Societe Francaise d'Oncologie Pediatrique (2001) The Societe Francaise d'Oncologie Pediatrique LMB89 protocol: highly effective multiagent chemotherapy tailored to the tumor burden and initial response in 561 unselected children with B-cell lymphomas and L3 leukemia. Blood 97:3370-3379

22. Patte C, Auperin A, Gerrard M, Michon J, Pinkerton R, Sposto R, Weston C, Raphael M, Perkins SL, McCarthy K, Cairo MS, FAB/ LMB96 International Study Committee (2007) Results of the randomized international FAB/LMB96 trial for intermediate risk Bcell non-Hodgkin lymphoma in children and adolescents: it is possible to reduce treatment for the early responding patients. Blood 109:2773-2780 
23. Cairo MS, Gerrard M, Sposto R, Auperin A, Pinkerton CR, Michon J, Weston C, Perkins SL, Raphael M, McCarthy K, Patte C, FAB LMB96 International Study Committee (2007) Results of a randomized international study of high-risk central nervous system B non-Hodgkin lymphoma and B acute lymphoblastic leukemia in children and adolescents. Blood 109:2736-2743

24. Dutch Childhood Oncology Group (2016) SKION B-NHL/B-ALL 2008. https://www.skion.nl/workspace/uploads/Final-B-NHL BALL-2008-10Mar2016.pdf

25. Dutch Childhood Oncology Group (2016) DCOG NBL 2009 Treatment Protocol. https://www.skion.nl/workspace/uploads/ DCOG-NBL2009_protocol_amend-1-1_febr2015-final_1.pdf

26. National Cancer Institute (2010) Common terminology criteria for adverse events v4.0 NCI, NIH, DHHS. NIH publication \# 09-7473. http://evs.nci.nih.gov/ftp1/CTCAE/CTCAE_4.03_2010-06-14_ QuickReference_8.5x11.pdf. Accessed May $29200 \overline{9}$

27. van Vliet MJ, Tissing WJ, Rings EH, Koetse HA, Stellaard F, Kamps WA, de Bont ES (2009) Citrulline as a marker for chemotherapy induced mucosal barrier injury in pediatric patients. Pediatr Blood Cancer 53:1188-1194

28. Blijlevens NM, Lutgens LC, Schattenberg AV, Donnelly JP (2004) Citrulline: a potentially simple quantitative marker of intestinal epithelial damage following myeloablative therapy. Bone Marrow Transplant 34:193-196

29. Crenn P, Vahedi K, Lavergne-Slove A, Cynober L, Matuchansky C, Messing B (2003) Plasma citrulline: a marker of enterocyte mass in villous atrophy-associated small bowel disease. Gastroenterology 124:1210-1219

30. Crenn P, Messing B, Cynober L (2008) Citrulline as a biomarker of intestinal failure due to enterocyte mass reduction. Clin Nutr 27: 328-339

31. Lutgens LC, Blijlevens NM, Deutz NE, Donnelly JP, Lambin P, de Pauw BE (2005) Monitoring myeloablative therapy-induced small bowel toxicity by serum citrulline concentration: a comparison with sugar permeability tests. Cancer 103:191-199
32. Lutgens LC, Deutz N, Granzier-Peeters M, Beets-Tan R, De Ruysscher D, Gueulette J, Cleutjens J, Berger M, Wouters B, von Meyenfeldt M, Lambin P (2004) Plasma citrulline concentration: a surrogate end point for radiation-induced mucosal atrophy of the small bowel. A feasibility study in 23 patients. Int J Radiat Oncol Biol Phys 60:275-285

33. van Eijk HM, Rooyakkers DR, Deutz NE (1993) Rapid routine determination of amino acids in plasma by high-performance liquid chromatography with a 2-3 microns Spherisorb ODS II column. J Chromatogr 620:143-148

34. Demacker PN, Beijers AM, van Daal H, Donnelly JP, Blijlevens NM, van den Ouweland JM (2009) Plasma citrulline measurement using UPLC tandem mass-spectrometry to determine small intestinal enterocyte pathology. J Chromatogr B Analyt Technol Biomed Life Sci 877:387-392

35. van der Velden WJ, Herbers AH, Bruggemann RJ, Feuth T, Peter Donnelly J, Blijlevens NM (2013) Citrulline and albumin as biomarkers for gastrointestinal mucositis in recipients of hematopoietic SCT. Bone Marrow Transplant 48:977-981

36. Joffe A, Anton N, Lequier L, Vandermeer B, Tjosvold L, Larsen B, Hartling L (2016) Nutritional support for critically ill children. Cochrane Database Syst Rev (5):CD005144. doi:10.1002/ 14651858.CD005144.pub3

37. Fivez T, Kerklaan D, Mesotten D, Verbruggen S, Wouters PJ, Vanhorebeek I, Debaveye Y, Vlasselaers D, Desmet L, Casaer MP, Garcia Guerra G, Hanot J, Joffe A, Tibboel D, Joosten K, Van den Berghe G (2016) Early versus late parenteral nutrition in critically ill children. N Engl J Med 374:1111-1122

38. Azarnoush S, Bruno B, Beghin L, Guimber D, Nelken B, YakoubAgha I, Seguy D (2012) Enteral nutrition: a first option for nutritional support of children following allo-SCT? Bone Marrow Transplant 47:1191-1195

39. Ward EJ, Henry LM, Friend AJ, Wilkins S, Phillips RS (2015) Nutritional support in children and young people with cancer undergoing chemotherapy. Cochrane Database Syst Rev (8): CD003298. doi:10.1002/14651858.CD003298.pub3 